\title{
Tables, Figures, and Maps
}

TABLES

1. Costs of the Bureau-Corps Competition 15

2. Increase in Federal Output per Man-Year 32

3. Summary of Propositions 80

4. Design Trade-offs 115

5. Comparing Redundancy and Monopoly 248

FIGURES

1. Interdependent Systems 44

2. Systems Vulnerable to Common Disturbance 45

3. $m \times n$ Communications System 51

4. Systems with Equal Means and Differing Riskiness

5. The Cases' Categories $\quad 81$

6. Relation of Integration and Monopoly 179

7. Washington Metropolitan Area Transit Authority: Present Organization

8. Washington Metropolitan Area Transit Authority (1977)

9. Relation Between Competition and Technical Norms

10. Reduction of Uncertainty 221

11. Estimates of Metro's Cost 222

12. Patterns of Political Support and Opposition 267

13. Alternatives with Equal Means and Differing Riskiness 
X TABLES, FIGURES, AND MAPS

14. Alternatives with Different Means and Differing Riskiness

15. Types of Policy Sectors

16. Effect of Technological Differences on Feasibility of Redundancy

17. Distribution of Costs and Benefits

MAPS

1. BART and the Bay Area

2. Metro and the Washington, D.C., Area 